\title{
Upper Respiratory Infection, CTCAE
}

National Cancer Institute

\section{Source}

National Cancer Institute. Upper Respiratory Infection, CT CAE. NCI Thesaurus. Code C143896.

A disorder characterized by an infectious process involving the upper respiratory tract (nose, paranasal sinuses, pharynx, larynx, or trachea). 